\section{(2) \\ BRAZIULIAN JOURNAL \\ OF MEDICAL AND BIOLOGICAL RESEARCH}

www.bjournal.com.br
ISSN 0100-879X

Volume 45 (5) 376-472 May 2012

BIOMEDICAL SCIENCES

AND

CLINICAL INVESTIGATION

Braz J Med Biol Res, May 2012, Volume 45(5) 401-407

doi: $10.1590 / S 0100-879 X 2012007500039$

Protection against neurotoxicity by an autophagic mechanism

Kangyong Liu, Jiankang Huang, Rongfu Chen, Ting Zhang, Liwei Shen, Jiajun Yang and Xiaojiang Sun

The Brazilian Journal of Medical and Biological Research is partially financed by

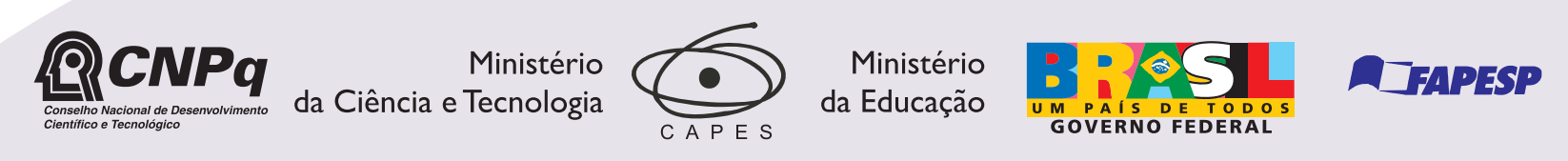

Institutional Sponsors

Scied
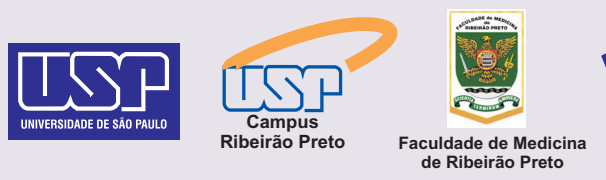

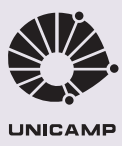

$\oplus$ SHIMADZU

Associaçăo
Fundo de Incentivo
à Pesquisa

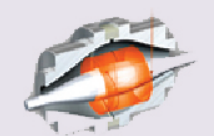

lore High - Performance MS Orbitrap Technology analitica Thermo 


\title{
Protection against neurotoxicity by an autophagic mechanism
}

\author{
Kangyong Liu¹, Jiankang Huang ${ }^{1}$, Rongfu Chen ${ }^{1}$, Ting Zhang ${ }^{1}$, Liwei Shen², \\ Jiajun Yang ${ }^{1}$ and Xiaojiang Sun ${ }^{1}$
}

${ }^{1}$ Department of Neurology, Affiliated Sixth People's Hospital, Shanghai Jiaotong University, Shanghai, China

2Department of Neurology, Fifth People's Hospital, Fudan University, Shanghai, China

\begin{abstract}
The objective of the present study was to investigate the effects of 3-n-butylphthalide (NBP) on a 1-methyl-4-phenylpyridinium $\left(\mathrm{MPP}^{+}\right)$-induced cellular model of Parkinson's disease (PD) and to illustrate the potential mechanism of autophagy in this process. For this purpose, rat PC12 pheochromocytoma cells were treated with $\mathrm{MPP}^{+}(1 \mathrm{mM})$ for $24 \mathrm{~h}$ following pretreatment with NBP $(0.1 \mathrm{mM})$. Cell metabolic viability was determined by the MTT assay and cell ultrastructure was examined by transmission electron microscopy. The intracellular distribution and expression of $\alpha$-synuclein and microtubule-associated protein light chain 3 (LC3) were detected by immunocytochemistry and Western blotting. Our results demonstrated that: 1) NBP prevented $\mathrm{MPP}^{+}$-induced cytotoxicity in PC12 cells by promoting metabolic viability. 2) NBP induced the accumulation of autophagosomes in $\mathrm{MPP}^{+}$-treated PC12 cells. 3) Further study of the molecular mechanism demonstrated that NBP enhanced the colocalization of $\alpha$-synuclein and LC3 and up-regulated the protein level of LC3-II. These results demonstrate that NBP protects PC12 cells against $\mathrm{MPP}^{+}$-induced neurotoxicity by activating autophagy-mediated $\alpha$-synuclein degradation, implying that it may be a potential effective therapeutic agent for the treatment of PD.
\end{abstract}

Key words: 3-N-butylphthalide; Parkinson's disease; a-synuclein; PC12 cells; Autophagy

\section{Introduction}

Autophagy is a well-characterized process by which cells degrade cytoplasmic materials, including intracellular organelles, proteins, and other components and recycle them in response to nutrient-limited conditions or amino acid starvation (1). Autophagy involves the formation of double-membrane structures, termed autophagosomes or autophagic vacuoles, which fuse with the lysosomal membrane to form the single-membrane autolysosome, where the components are degraded (2). A variety of autophagy genes have been found to be specifically required for the formation of autophagosomes and for the autophagy process (3). Autophagy induction or autophagy activation has been recognized by the accumulation of autophagosomes and autolysosomes. Moreover, the conversion of microtubuleassociated protein light chain 3-I (LC3-I, cytosolic form) to LC3-II (lipidated form) is another reliable marker for increased autophagic activity (4).

Several lines of evidence indicate that autophagy is associated with various human diseases, including several neurodegenerative disorders such as Parkinson's disease
(PD), Alzheimer's disease (AD), and Huntington's disease (HD) (5). The presence of abnormal protein inclusions has been accepted as a common pathological hallmark of these disorders, including mutant $\alpha$-synucleins (A53T and A30P) in $P D$, neurofibrillary tangles in $A D$, and polyglutamine expansions in HD (6-9). Therefore, efficient clearance of aggresomes by the autophagic process appears to be essential for maintaining cellular metabolic turnover and homeostasis. It has been demonstrated that $\alpha$-synuclein can be degraded by both autophagic and proteosomal degradation pathways in PC12 cells (10). Stimulation of autophagic activity by rapamycin enhanced the clearance of $\alpha$-synuclein (10).

The homogeneous I-isomer of 3-n-butylphthalide (NBP) was extracted from seeds of Apium graveolens Linn (11). Previous studies have shown that NBP is beneficial for treating stroke by multiple actions, including decreasing the area of cerebral infarct in focal cerebral ischemic rats (12), improving energy metabolism in mice with complete brain ischemia (13), reducing oxidative damage (14), and

Correspondence: Xiaojiang Sun, Department of Neurology, Affiliated Sixth People's Hospital of Shanghai Jiaotong University, Shanghai 200233, China. Fax: +86-21-6436-9181. E-mail: sunxj155@sohu.com

Received October 20, 2011. Accepted February 29, 2012. Available online March 23, 2012. Published May 7, 2012. 
inhibiting the inflammatory response (15) in rats with focal cerebral ischemia. Synthetic dl-NBP was approved by the State Food and Drug Administration of China for clinical use in patients with stroke in 2002. Current reports show that NBP prevented oxidative damage and reduced mitochondrial dysfunction in a 1-methyl-4-phenylpyridinium $\left(\mathrm{MPP}^{+}\right)$-induced cellular model of PD (16). Nevertheless, the detailed molecular mechanisms underlying the neuroprotective roles of NBP in PD are not understood.

Therefore, the objective of the present study was to determine whether NBP isolated from seeds of Apium graveolens Linn protects $\mathrm{PC} 12$ neuronal cells, a widely applied cellular model of PD, from $\mathrm{MPP}^{+}$-induced neurotoxicity. Importantly, this study provides insights into the neuroprotective mechanisms of NBP in $\mathrm{MPP}^{+}$-induced PC12 cells involving autophagy-mediated $\alpha$-synuclein degradation.

\section{Material and Methods}

\section{Reagents}

NBP was purchased from Shijiazhuang Pharmaceutical Co., Ltd. (China). 3-(4,5-Dimethylthiazol-2-yl)-2,5-diphenyltetrazolium bromide (MTT) was obtained from Sigma-Aldrich (USA). Neonatal bovine serum (NBS) and Dulbecco's modified Eagle's medium (DMEM) were purchased from GIBCO (USA). Primary antibodies for a-synuclein (CST, USA), LC3 (CST), and $\alpha$-actin were obtained from Santa Cruz Biotechnology (USA). Horseradish peroxidase (HRP)conjugated anti-rabbit IgG was provided by Jingmei Biotech Co., Ltd. (China). Secondary antibodies used for immunofluorescence analysis, including goat anti-rabbit IgG-FITC and goat anti-mouse IgG-TRITC, were purchased from the Beyotime Institute of Biotechnology (China).

\section{Cell culture and drug treatment}

Highly differentiated rat PC12 pheochromocytoma cells were purchased from the Institute of Cell Biology, Chinese Academy of Sciences (Shanghai, China). Cells were cultured in DMEM supplemented with $10 \%$ NBS at $37^{\circ} \mathrm{C}$ in a humidified environment containing $5 \% \mathrm{CO}_{2}$ and $95 \%$ room air. For drug treatments, cells were treated in the log phase with $\mathrm{MPP}^{+}(1 \mathrm{mM})$ in the presence or absence of NBP $(0.1$ $\mathrm{mM}$ ) for $3,6,12,24,48$, and $72 \mathrm{~h}$.

\section{Determination of cell metabolic viability}

The MTT assay was used to examine the metabolic viability of the cells. Cells were seeded on a 96-well plate at a density of $1 \times 10^{4}$ cells/well. The following day, cells received different drug treatments. After the appropriate incubation time, the drugs were removed and cells were washed with phosphate-buffered saline (PBS). Then, 200 $\mu \mathrm{L}$ MTT $(0.5 \mathrm{mg} / \mathrm{mL}$ diluted in culture medium) was added to each well. After an additional $3 \mathrm{~h}$ of incubation at $37^{\circ} \mathrm{C}$ in the dark, the MTT solution was removed and $200 \mu \mathrm{L}$ dimethyl sulfoxide was added to each well to solubilize the metabolic products of MTT. The absorbance of the dissolved formazan was measured at $570 \mathrm{~nm}\left(\mathrm{~A}_{570}\right)$ with a microplate reader (2D-Quent, GE Amersham, USA). The percentage of cell metabolic viability was calculated using the following formula: metabolic viability $(\%)=\left(A_{570}\right.$, sample $/$ A 570 , control) ${ }^{*} 100$.

\section{Transmission electron microscopy analysis}

Treated cells were fixed with $2.5 \%$ glutaraldehyde in $0.1 \mathrm{M}$ sodium cacodylate-buffered solution for $2 \mathrm{~h}$ and then post-fixed with $1 \% \mathrm{OsO}_{4}$ for $2 \mathrm{~h}$. After dehydrating in a graded ethanol series and acetone washes, samples were embedded in Epon812. Ultrathin sections were stained with uranyl acetate and lead citrate and examined under a JEM-1230 transmission electron microscopy (Japan).

\section{Immunocytochemical analysis}

Cells were fixed with cold $4 \%$ paraformaldehyde for 20 min, washed with PBS, permeabilized with $0.1 \%$ Triton $\mathrm{X}-100$ for $20 \mathrm{~min}$, and stained with primary antibodies $(1: 1000)$ in $\mathrm{PBS}$ at $37^{\circ} \mathrm{C}$ for $0.5 \mathrm{~h}$. Cells were subsequently treated with the secondary antibodies $(1: 1000)$ at $37^{\circ} \mathrm{C}$ for $30 \mathrm{~min}$. After washing with PBS three times, the nucleus was stained with Hoechst 33342 for 5 min. Images were visualized under a confocal laser scanning microscope (Leica TCS SP5, Germany).

\section{Western blotting}

The treated cells were washed with ice-cold PBS and incubated with lysis buffer containing $10 \mathrm{mM}$ Tris- $\mathrm{HCl}, \mathrm{pH}$ 7.4, $0.25 \mathrm{M}$ sucrose, $1 \mathrm{mM} \mathrm{MgCl} 2,2.5 \mathrm{mM}$ EDTA, $1 \mathrm{mM}$ EGTA, $1 \mathrm{mM}$ dithiothreitol, $1.25 \mathrm{mg} / \mathrm{mL}$ pepstatin $\mathrm{A}, 10 \mathrm{mg} /$ $\mathrm{mL}$ leupeptin, $2.5 \mathrm{mg} / \mathrm{mL}$ aprotinin, $0.5 \mathrm{mM}$ phenylmethylsulfonyl fluoride, $0.1 \mathrm{mM} \mathrm{Na}_{3} \mathrm{VO}_{4}, 50 \mathrm{mM} \mathrm{NaF}$, and $2 \mathrm{mM}$ $\mathrm{Na}_{4} \mathrm{P}_{2} \mathrm{O}_{7}$. Protein concentration was determined by the method of Bradford (17). Total cell protein was separated by $12 \%$ sodium dodecyl sulfate-polyacrylamide gel electrophoresis (SDS-PAGE) and transferred to a polyvinylidene difluoride (PVDF) membrane (Millipore, USA). Membranes were blocked with $5 \%$ non-fat milk and then incubated with antibodies to $\alpha$-synuclein, LC3, or $\alpha$-actin (1:1000) and HRP-conjugated anti-rabbit secondary antibody. The bound antibody complexes were detected using an electrogenerated chemiluminescence reagent (Amersham, USA). Band images were analyzed with Image Master VDS (Pharmacia Biotech, USA). The intensities of the immunoreactive bands were quantified by densitometric analysis.

\section{Statistical analysis}

Data were analyzed using the SPSS 17.0 software and are reported as means \pm SD of at least three independent experiments carried out in triplicate. Statistical differences between values were determined by analysis of variance (ANOVA) followed by the Tukey post hoc test. The level of significance was set at $\mathrm{P}<0.05$ or 0.01 . 


\section{Results}

\section{NBP prevented MPP ${ }^{+}$-induced neurotoxicity in PC12 cells}

An MTT assay was performed to evaluate the effects of drug administration on the metabolic viability of cells. As shown in Figure 1, $\mathrm{MPP}^{+}$treatment for $3 \mathrm{~h}$ suppressed cell metabolic viability and resulted in an approximate $30 \%$ reduction of metabolic viability ( $P<0.01$ versus control). Nevertheless, $0.1 \mathrm{mM}$ NBP promoted the metabolic viability of PC12 cells at each time compared to the cells treated with $\mathrm{MPP}^{+}$alone $(\mathrm{P}<0.01)$. Phase contrast photomicrographs show the differences in cell morphology among drug treatment groups. Twenty-four hours after MPP ${ }^{+}$treatment, some of the PC12 cells died, leaving cells that appeared shrunken and with short processes (Figure 2B). In contrast, in the NBP-treated groups the dendritic processes surrounding the cells were largely preserved (Figure 2C), suggesting that NBP protected neuronal cells from $\mathrm{MPP}^{+}$induced death.

\section{NBP induced the accumulation of autophagosomes in $\mathrm{MPP}^{+}$-treated $\mathrm{PC} 12$ cells}

To further explore the potential mechanism of the cytoprotective effect of NBP on $\mathrm{MPP}^{+}$-treated PC12 cells, transmission electron microscopy analysis was applied. In the control or only $\mathrm{MPP}^{+}$-treated groups, PC12 cells barely showed any vacuoles (Figure $3 A$ and B). In contrast, abundant vacuoles were present in NBP-treated PC12 cells (Figure 3C). These vacuoles resembled autophagosomes based on the presence of the double-membrane structure (Figure 3C, arrow). Moreover, single-membrane vesicles, namely autolysosomes, which contained high-density contents, were also observed after NBP treatment (Figure $3 \mathrm{C}$, arrowhead). These findings implied that NBP could induce the accumulation of autophagosomes in $\mathrm{MPP}^{+}$treated PC12 cells.
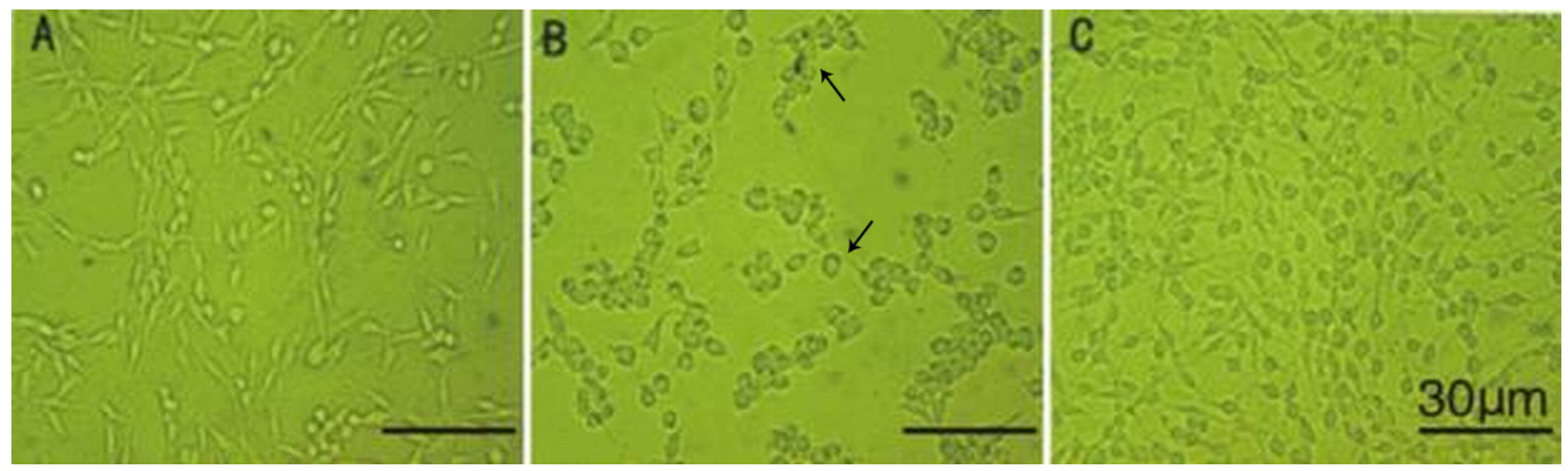

Figure 2. Morphological changes in PC12 cells with different treatments. Cell morphology was examined under a phase contrast microscope $24 \mathrm{~h}$ after incubation with phosphate-buffered saline $(A)$, 1-methyl-4-phenylpyridinium (MPP $\left.{ }^{+}\right)(B)$ and $\mathrm{MPP}^{+}$plus 3-nbutylphthalide (NBP) (C). Twenty-four hours after MPP ${ }^{+}$treatment, some of the PC12 cells died (arrows), leaving cells that appeared shrunken and with short processes $(B)$. In contrast, in the NBP-treated groups the dendritic processes surrounding the cells were largely preserved $(C)$, suggesting that NBP protected neuronal cells from MPP ${ }^{+}$-induced death.

\section{NBP promoted the colocalization of $\alpha$-synuclein and LC3 in MPP+-treated PC12 cells}

$P D$ is characterized by the presence of sporadic intraneuronal cytoplasmic inclusions known as Lewy bodies, which contain fibrillar $\alpha$-synuclein $(6,7)$. We next investigated the correlation between the autophagy marker protein LC3 and $\alpha$-synuclein. After treating cells with $\mathrm{MPP}^{+}$in the presence or absence of NBP for $24 \mathrm{~h}, \mathrm{PC} 12$ cells were double stained with anti- $\alpha$-synuclein and antiLC3 antibodies. The nuclei were visualized by Hoechst 33342 staining. As shown in Figure 4, both $\alpha$-synuclein and LC3 are distributed in the cytoplasm. Interestingly, promoted the colocalization of $\alpha$-synuclein and LC3 in $\mathrm{MPP}^{+}$-treated cells, implying that $\alpha$-synuclein might

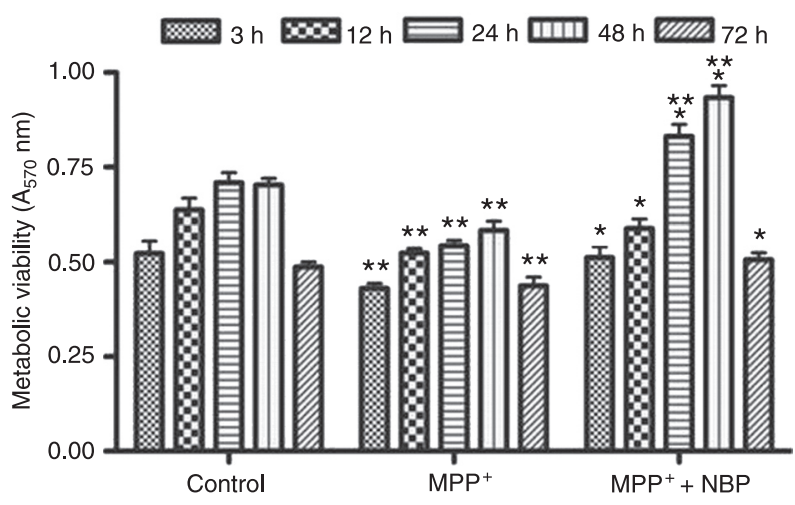

Figure 1. 3-n-Butylphthalide (NBP) prevented 1-methyl-4phenylpyridinium $\left(\mathrm{MPP}^{+}\right)$-induced neurotoxicity in $\mathrm{PC} 12$ cells. $\mathrm{PC} 12$ cells were treated with $1 \mathrm{mM} \mathrm{MPP}^{+}$or $1 \mathrm{mM} \mathrm{MPP}^{+}$plus 0.1 mM NBP for $3,12,24,48$, or $72 \mathrm{~h}$. Cells treated with phosphateof cells was assessed by the 3-(4,5-dimethylthiazol-2-yl)-2,5diphenyltetrazolium bromide (MTT) assay. ${ }^{*} \mathrm{P}<0.05$ compared to $\mathrm{MPP}^{+}$treatment; ${ }^{* *} \mathrm{P}<0.01$ compared to control (ANOVA followed by the Tukey post hoc test). buffered saline were used as control. The metabolic viability 
be degraded by an autophagy-lysosome system, and NBP enhanced the degradation of $\alpha$-synuclein upon $\mathrm{MPP}^{+}$treatment.

\section{Effects of NBP on the expression of $\alpha$-synuclein and LC3 protein in MPP $^{+}$-treated PC12 cells}

Since the enhanced colocalization of $\alpha$-synuclein and LC3 was observed in NBP-treated PC12 cells, it is possible that NBP stimulated the degradation of $\alpha$-synuclein by an autophagic process. Therefore, the intracellular a-synuclein and LC3 protein levels were determined by Western blot. As shown in Figure $5 \mathrm{~A}$, incubation of $\mathrm{MPP}^{+}$for $24 \mathrm{~h}$ significantly up-regulated the expression of the $\alpha$-synuclein protein in PC12 cells $(P<0.01$ compared to control), whereas NBP inhibited the elevated expression of $\alpha$-synuclein induced by $\mathrm{MPP}^{+}$. NBP at $0.1 \mathrm{mM}$ inhibited a-synuclein protein expression in cells receiving $\mathrm{MPP}^{+}$alone by $60 \%(P<0.01)$. Moreover the level of the $\alpha$-synuclein protein in the NBP combination group was lower than in control $(P<0.01)$. The application of NBP also dramatically up-regulated the expression of the LC3-II protein, which is an essential biomarker for autophagy activation (18) (Figure $5 B)$. NBP at $0.1 \mathrm{mM}$ increased LC3-II expression 1.3-fold in the cells receiving $\mathrm{MPP}^{+}$alone. These results suggest that NBP might promote the degradation of $\alpha$-synuclein by activating autophagic processes.

\section{Discussion}

The present study demonstrates the neuroprotective effects of NBP extracted from seeds of $A$. graveolens Linn on $\mathrm{MPP}^{+}$-induced $\mathrm{PC} 12$ cells, (C, arrowhead).
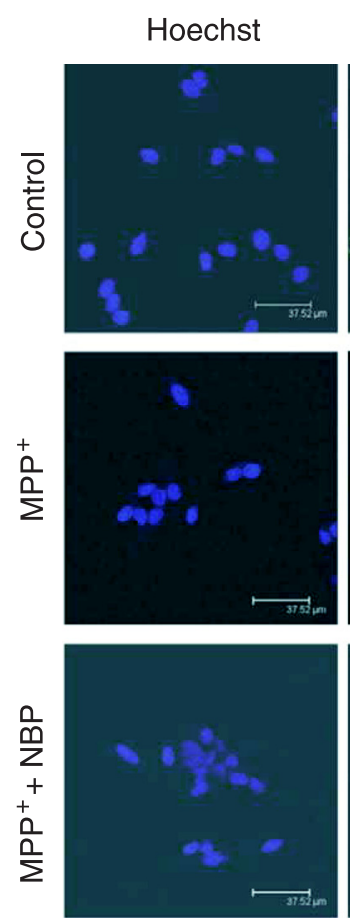

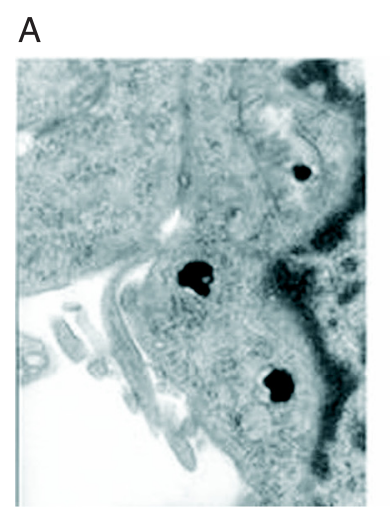

which is a widely applied cellular model of PD. Our findings also reveal that NBP prevented $\mathrm{MPP}^{+}$-induced cytotoxicity in PC12 cells by stimulating autophagy-mediated $\alpha$-synuclein
B

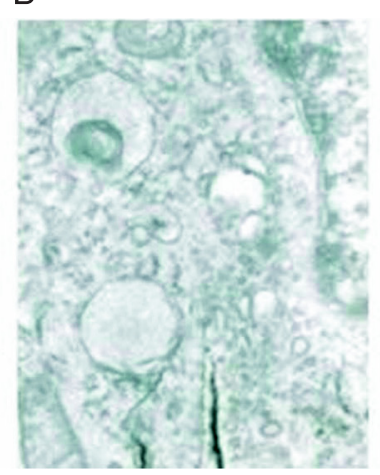

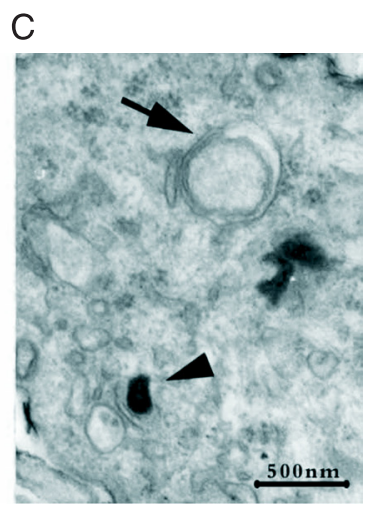

Figure 3. Ultrastructure of PC12 cells examined by transmission electron microscopy $24 \mathrm{~h}$ after incubation with phosphate-buffered saline $(A)$, 1-methyl-4-phenylpyridinium $\left(\mathrm{MPP}^{+}\right)(B)$, and $\mathrm{MPP}^{+}$plus 3-n-butylphthalide (NBP) (C). In the control and only $\mathrm{MPP}^{+}$-treated groups, PC12 cells barely showed any vacuoles $(A, B)$. In contrast, abundant vacuoles were present in NBPtreated PC12 cells $(C)$. These vacuoles resembled autophagosomes based on the presence of the double-membrane structure $(C$, arrow). Moreover, single-membrane vesicles, namely autolysosomes, which contained high-density contents, were also observed after NBP treatment

$\alpha$-synuclein

LC3
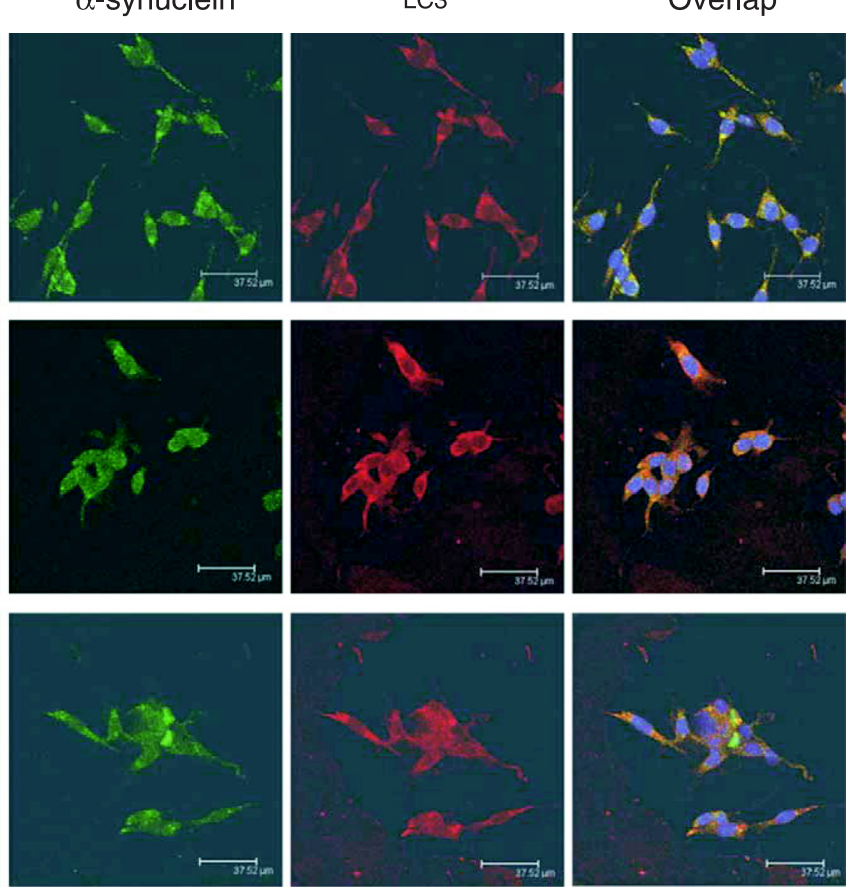

Figure 4. 3-n-Butylphthalide (NBP) promoted the colocalization of $\alpha$-synuclein and light chain 3 (LC3) in 1-methyl-4-phenylpyridinium (MPP ${ }^{+}$)-treated PC12 cells. The treated cells were immunostained with anti- $\alpha$-synuclein (green) and anti-LC3 (red) antibodies. Nuclei were further stained with Hoechst 33342 (blue). Immunoreactivity was visualized under a confocal laser scanning microscope. Scale bars $=37.52 \mu \mathrm{m}$. 
degradation, suggesting that NBP might be promising for the clinical treatment of patients with PD.

$P D$ is characterized by the degeneration of dopaminergic neurons in the substantia nigra, the presence of Lewy bodies in neurons, and the accumulation of $\alpha$-synuclein mutations in these bodies (19). 6-Hydroxydopamine (6-OHDA) and 1-methyl-4phenyl-1,2,3,6-tetrahydropyridine (MPTP) are neurotoxins commonly used to induce the degeneration of dopaminergic neurons in in vitro studies (20). In addition, $\mathrm{MPP}^{+}$, the active metabolite of MPTP, can cause selective neurotoxic damage to dopaminergic neurons and thus has been widely applied to generate in vitro cell models of PD (20). Therefore, $\mathrm{MPP}^{+}$-induced PC12 cell death may provide a stable and reliable cell model for estimating the effects of anti-PD drugs.

Since understanding the mechanisms of $\mathrm{MPP}^{+}$-induced neurotoxicity or the drug interference might provide hints for uncovering the etiology of PD, numerous investigators have taken steps to address these important issues. It has been demonstrated that mutant $\alpha$-synuclein enhanced the toxicity of $\mathrm{MPP}^{+}$in PC12 cells by increasing the generation of intracellular reactive oxygen species (ROS) (21). Several drugs protect PC12 cells from death induced by $\mathrm{MPP}^{+}$administration. For example, the anti-leprosy antibiotic rifampicin dramatically reduces $\mathrm{MPP}^{+}$-induced cell apoptosis (22) and curcumin protects PC12 cells against $\mathrm{MPP}^{+}$-induced apoptosis by a bcl-2-mitochondria-ROSiNOS signaling pathway (23). In the present study, our results demonstrate that a novel neural protective agent, NBP, can protect against MPP ${ }^{+}$-induced neurotoxicity via activation of an autophagic process. The typical morphological changes of apoptotic cell death, including chromatin condensation, aggregation at the periphery of the nucleus, and nuclear fragmentation (Figure $3 \mathrm{~B}$ ), were detected by transmission electron microscopy in $\mathrm{MPP}^{+}$-treated $\mathrm{PC} 12$ cells. After combined treatment with NBP, no characteristics of apoptosis were detected, while the accumulation of both autophagosomes and autolysosomes occurred in PC12 cells (Figure $3 \mathrm{C}$ ). Autophagy is type 2 programmed cell death, which is a mechanism distinct from apoptosis (24). In melanized neurons of the substantia nigra in patients with
PD, both apoptotic and autophagic neuron degeneration has been observed (25). Since apoptosis and autophagy share several common pathways (26), it is possible that both pathways are involved in and contributed to the process of NBP-induced cytoprotection in a PD cell model. However, based on the present observations, the exact interaction between autophagy and apoptosis remains unclear.

Autophagy-mediated clearance of aggresomes has been implicated in many neurodegenerative diseases such as PD and AD. In PD, aberrant $\alpha$-synuclein degradation is observed in the disease pathogenesis. The A53T and $\mathrm{A} 30 \mathrm{P}$ point mutations in $\alpha$-synuclein are substrates of autophagy, and the clearance of these mutant forms will be retarded if the autophagic process is inhibited (10). Both autophagic and proteosomal degradation pathways have been proposed to mediate $\alpha$-synuclein clearance (10). Stimulation of autophagic activity by rapamycin can enhance the degradation of a-synuclein (10). Recently, the novel mTOR-independent autophagy enhancer, trehalose, has also been shown to accelerate the clearance of aggregate-prone proteins like mutant huntingtin and a-synuclein, and consequently protect cells from proapoptotic insults (27). In the current study, $\mathrm{MPP}^{+}$significantly elevated $\alpha$-synuclein accumulation, which was abolished by NBP addition (Figure 5A). Furthermore, NBP treatment resulted in the up-regulation of LC3-II (Figure 5B) (18). The 
enhanced colocalization of LC3 and a-synuclein was also detected upon combined MTT and NBP treatment (Figure 4). These results strongly suggest that NBP promotes intracellular autophagic activity and subsequently enhances the degradation of $\alpha$-synuclein. Thus, it can be concluded that autophagy protects against PD through self-digestion of mis-aggregated proteins, such as $\alpha$-synuclein.

NBP has been used for the clinical therapy of stroke in China for years. A large body of evidence has shown the striking anti-ischemic effects of NBP. For example, it reduces stroke incidence and protects against oxidative stress and mitochondrial damage (28). It decreases the area of cerebral infarct and ameliorates brain edema and blood-brain barrier damage in rats with middle cerebral artery occlusion $(12,29)$. It also increases ATP level in rats with cerebral ischemia, and therefore prevents mitochondrial dysfunction resulting from ATP depletion (30). Our previous study revealed that NBP had the ability to suppress the release of cytochrome $\mathrm{C}$, to stimulate the up-regulation of vascular endothelial growth factor, and subsequently protect against oxidative stress in diabetic rats (31). Moreover, NBP could reduce the amyloid $\beta$ peptide generation promoted by diabetes in ischemia by inhibiting over-activated autophagy (32). Together with our observations, these results indicate

\section{References}

1. Eskelinen EL. Maturation of autophagic vacuoles in mammalian cells. Autophagy 2005; 1: 1-10.

2. Klionsky DJ, Emr SD. Autophagy as a regulated pathway of cellular degradation. Science 2000; 290: 1717-1721.

3. Kiselyov K, Jennigs JJ Jr, Rbaibi Y, Chu CT. Autophagy, mitochondria and cell death in lysosomal storage diseases. Autophagy 2007; 3: 259-262.

4. Kabeya Y, Mizushima N, Ueno T, Yamamoto A, Kirisako T, Noda T, et al. LC3, a mammalian homologue of yeast Apg8p, is localized in autophagosome membranes after processing. EMBO J 2000; 19: 5720-5728.

5. Rubinsztein DC, DiFiglia M, Heintz N, Nixon RA, Qin ZH, Ravikumar B, et al. Autophagy and its possible roles in nervous system diseases, damage and repair. Autophagy 2005; 1: 11-22.

6. Spillantini MG, Crowther RA, Jakes R, Hasegawa M, Goedert M. a-Synuclein in filamentous inclusions of Lewy bodies from Parkinson's disease and dementia with Lewy bodies. Proc Natl Acad Sci U S A 1998; 95: 6469-6473.

7. Baba M, Nakajo S, Tu PH, Tomita T, Nakaya K, Lee VM, et al. Aggregation of alpha-synuclein in Lewy bodies of sporadic Parkinson's disease and dementia with Lewy bodies. Am J Pathol 1998; 152: 879-884.

8. Ross CA, Poirier MA. Protein aggregation and neurodegenerative disease. Nat Med 2004; 10 (Suppl): S10-S17.

9. Yamamoto A, Cremona ML, Rothman JE. Autophagy-mediated clearance of huntingtin aggregates triggered by the insulin-signaling pathway. J Cell Biol 2006; 172: 719-731.

10. Webb JL, Ravikumar B, Atkins J, Skepper JN, Rubinsztein DC. Alpha-synuclein is degraded by both autophagy and the the NBP may achieve neuroprotective effects by regulating the autophagic process.

The present study reported the neuroprotective effects of NBP in an in vitro cell model of PD. NBP prevented $\mathrm{MPP}^{+}$-induced neurotoxicity in PC12 cells by stimulating autophagy-mediated $\alpha$-synuclein degradation, suggesting that NBP may have potential therapeutic effects for the treatment of PD patients. Future studies should be focused on exploring the potential mechanism of NBP-evoked a-synuclein clearance in $\mathrm{MPP}^{+}$-treated PC12 cells and the cross-talk between autophagy and apoptosis in this process.

\section{Acknowledgments}

Research supported by the National Natural Science Foundation of China (\#30970869), the Board of Health of Shanghai, China (\#2008086), by grants from the project of Shanghai Key Laboratory of Diabetes Mellitus (\#08DZ2230200), the Youth Key Project of Shanghai College of Medicine, Fudan University (\#09-L37), and by grants from the project of the Committee of Science and Technology of Minhang District Shanghai (\#2009MH2086). proteasome. J Biol Chem 2003; 278: 25009-25013.

11. Yang JS, Chen YW. Isolation and identification of the anticonvulsive constituents of Apium graveolens. Chin Pharmacol Bull 1984; 19: 670-671.

12. Liu XG, Feng YP. [Protective effect of dl-3-n-butylphthalide on ischemic neurological damage and abnormal behavior in rats subjected to focal ischemia]. Yao Xue Xue Bao 1995; 30: 896-903

13. Feng YP, Hu D, Zhang LY. [Effect of DL-butylphthalide (NBP) on mouse brain energy metabolism in complete brain ischemia induced by decapitation]. Yao Xue Xue Bao 1995; 30: 741-744.

14. Dong GX, Feng YP. [Effects of NBP on ATPase and antioxidant enzymes activities and lipid peroxidation in transient focal cerebral ischemic rats]. Zhongguo Yi Xue Ke Xue Yuan Xue Bao 2002; 24: 93-97.

15. Xu HL, Feng YP. Inhibitory effects of chiral 3-n-butylphthalide on inflammation following focal ischemic brain injury in rats. Acta Pharmacol Sin 2000; 21: 433-438.

16. Huang JZ, Chen YZ, Su M, Zheng HF, Yang YP, Chen J, et al. dl-3-n-Butylphthalide prevents oxidative damage and reduces mitochondrial dysfunction in an $\mathrm{MPP}(+)$-induced cellular model of Parkinson's disease. Neurosci Lett 2010; 475: 89-94.

17. Bradford MM. A rapid and sensitive method for the quantitation of microgram quantities of protein utilizing the principle of protein-dye binding. Anal Biochem 1976; 72: 248-254.

18. Yang Y, Fukui K, Koike T, Zheng X. Induction of autophagy in neurite degeneration of mouse superior cervical ganglion neurons. Eur J Neurosci 2007; 26: 2979-2988. 
19. Kahle PJ, Haass C, Kretzschmar HA, Neumann M. Structure/function of alpha-synuclein in health and disease: rational development of animal models for Parkinson's and related diseases. J Neurochem 2002; 82: 449-457.

20. Dauer W, Przedborski S. Parkinson's disease: mechanisms and models. Neuron 2003; 39: 889-909.

21. Qian JJ, Cheng YB, Yang YP, Mao CJ, Qin ZH, Li K, et al. Differential effects of overexpression of wild-type and mutant human alpha-synuclein on MPP+-induced neurotoxicity in PC12 cells. Neurosci Lett 2008; 435: 142-146.

22. Xu J, Wei C, Xu C, Bennett MC, Zhang G, Li F, et al. Rifampicin protects PC12 cells against MPP+-induced apoptosis and inhibits the expression of an alpha-synuclein multimer. Brain Res 2007; 1139: 220-225.

23. Chen J, Tang XQ, Zhi JL, Cui Y, Yu HM, Tang EH, et al. Curcumin protects PC12 cells against 1-methyl-4-phenylpyridinium ion-induced apoptosis by bcl-2-mitochondria-ROS-iNOS pathway. Apoptosis 2006; 11: 943-953.

24. Edinger $\mathrm{AL}$, Thompson $\mathrm{CB}$. Death by design: apoptosis, necrosis and autophagy. Curr Opin Cell Biol 2004; 16: 663669.

25. Anglade P, Vyas S, Javoy-Agid F, Herrero MT, Michel PP, Marquez J, et al. Apoptosis and autophagy in nigral neurons of patients with Parkinson's disease. Histol Histopathol 1997; 12: 25-31.

26. Maiuri MC, Zalckvar E, Kimchi A, Kroemer G. Self-eating and self-killing: crosstalk between autophagy and apoptosis. Nat
Rev Mol Cell Biol 2007; 8: 741-752.

27. Sarkar S, Davies JE, Huang Z, Tunnacliffe A, Rubinsztein DC. Trehalose, a novel mTOR-independent autophagy enhancer, accelerates the clearance of mutant huntingtin and alpha-synuclein. J Biol Chem 2007; 282: 5641-5652.

28. Li L, Zhang B, Tao Y, Wang Y, Wei H, Zhao J, et al. DL-3-nbutylphthalide protects endothelial cells against oxidative/ nitrosative stress, mitochondrial damage and subsequent cell death after oxygen glucose deprivation in vitro. Brain Res 2009; 1290: 91-101.

29. Chong ZZ, Feng YP. DI-3-n-butylphthalide attenuates reperfusion-induced blood-brain barrier damage after focal cerebral ischemia in rats. Zhongguo Yao Li Xue Bao 1999; 20: 696-700.

30. Yan CH, Feng YP, Zhang JT. Effects of dl-3-n-butylphthalide on regional cerebral blood flow in right middle cerebral artery occlusion rats. Zhongguo Yao Li Xue Bao 1998; 19: 117120.

31. Zhang T, Jia W, Sun X. 3-n-Butylphthalide (NBP) reduces apoptosis and enhances vascular endothelial growth factor (VEGF) up-regulation in diabetic rats. Neurol Res 2010; 32 : 390-396.

32. Zhang T, Yan W, Li Q, Fu J, Liu K, Jia W, et al. 3-nButylphthalide (NBP) attenuated neuronal autophagy and amyloid-beta expression in diabetic mice subjected to brain ischemia. Neurol Res 2011; 33: 396-404. 